\title{
THE ENTOMOLOGICAL SOCIETY OF AMERICA.
}

\section{OFFICERS FOR THE YEAR I907.}

(Elected December 28, I906.)

President . . . . . . . . . . . . . . . . J. H. Comstock

First Vice President................ James Fletcher

Second Vice President.................. Henry Skinner Secretary-Treasurer................ J. Chester Bradley

Additional Members of the Executive Committee.
W. M. WHEELER
J. B. Smith,
C. J. S. Bethune,
Herbert Osborn,
F. M. Webster,
C. W. Johnson.

OFFICERS FOR THE YEAR I9O8.

(Elected December 3 I, I907.)

President........................Wm. M. WheEler

First Vice President.................. J. B. Sмiтh

Second Vice President .................. J. S. Bethune

Secretary-Treasurer.................. Chester Bradley

Additional members of the Executive Committee.
J. H. Comstock,
J. G. Needham,
P. P. Calvert,
Herbert Osborn,
F. M. Webster,
V. L. Kellogg. 


\section{$2 \mathrm{BHL}$ Biodiversity Heritage Library}

1908. "Officers for the Year 1907." Annals of the Entomological Society of America 1, 3-3. https://doi.org/10.1093/aesa/1.1.3.

View This Item Online: https://www.biodiversitylibrary.org/item/38100

DOI: https://doi.org/10.1093/aesa/1.1.3

Permalink: https://www.biodiversitylibrary.org/partpdf/193694

\section{Holding Institution}

Smithsonian Libraries

\section{Sponsored by}

Smithsonian

\section{Copyright \& Reuse}

Copyright Status: NOT_IN_COPYRIGHT

This document was created from content at the Biodiversity Heritage Library, the world's largest open access digital library for biodiversity literature and archives. Visit BHL at https://www.biodiversitylibrary.org. 